\title{
A Comparison Between the International Standards PRINCE2 and PMBOK in Project Management
}

\author{
Sana`a Hassan Zubon ${ }^{1}$, Maher Kadhim Taher ${ }^{2}$ \\ \{ sanaahassanalenzi@stu.edu.iq ${ }^{1}$, Maher.altameemi@stu.edu.iq\} \\ Southern Technical University/Technical Institute/Basra/Department of mechanical Technologies, \\ $\operatorname{Iraq}^{1,2}$
}

\begin{abstract}
PRINCE2 developed the short for Projects IN Controlled Environments through observations and a summary of experiences of project management professionals, concerned users, and review committees from hundreds of organizations from the public and private sectors. This has produced a flexible tool for best practices in project management. To suit and adapt to the institution or organization and to be used and applied. With success regardless of the type or size of the projects to be managed. To specify the limits of delegated authority, the PRINCE2 project specified tolerances for each project objective. PRINCE2 lists variations set there are time, cost, quality, scope, risks, and benefits. The Project Management Framework, which is based on the PMBOK Quid is a prominent project technique from PMI In the United States, this method is very popular, but PRINCE2 is very popular and folk in Europe. PRINCE2 is a project management method that is based on seven principles. PMBOK Project Management Body of Knowledge a Guide to Project Management is PMP Project Management Professional from PMI standards Institute. PRINCE2 new method in Project Management to Future jobs.
\end{abstract}

Keywords: PRINCE2, PMBOK, IT, EIA ,CCTA, ISO, AXELOS, PMI, PMP, CPM.

\section{Introduction}

PRINCE2 dates back to 1989, when the British government developed it through the Central Computer and Communications Agency (CCTA), after developing it from a previous methodology for Project Management Technology called (PROMPT) under the Project Guide (PRINCE1), and after that, it became (PRINCE2) A government specification adopted by the United Kingdom for managing IT(Information and Communication Technology) projects, and its program and curriculum are prepared by the British Governmental Commercial Office. It is also used very widely in European countries, especially in IT projects and for all projects. PRINCE2 is a general project management method apply to big or small, it is popular in United Kingdom (UK).

The project is defined as "a set of tasks that must be completed in order to achieve a specified goal." A project, according to PRINCE2, is a temporary organization formed to introduce one or more business products under a business case.

The program is a flexible, temporary organizational structure designed to coordinate, organize, and monitor the implementation of a collection of connected projects and activities to achieve the organization's strategic goals and objectives.

It is the process of assessing a proposed project's possible environmental consequences (both positive and negative). 
The objective of this procedure is to provide decision-makers with the information they need to determine whether or not to proceed with the project.

A natural, chemical, biological, cultural, or socioeconomic effect on the ecosystem as a result of the project's operations is characterized as an environmental impact. Environmental impact assessment is training on what will be done before any project, for the main activities, or what will be done to ensure that no means will harm the environment in the short or long term, and it is the process by which the environmental impacts of an activity are predicted and described [1][2][15].

\section{Research problem}

One of the activities that must be performed and completed throughout a project is preparing for a project being the first to take place in PRINCE2 .Its purpose is to answer the question "Is this project feasible and deserving to be implemented?" And will the project succeed by being environmentally friendly? Every project starts with an idea, but it might not be a good idea. During this process, sufficient information is provided to the project management committee to do its part in selecting the good ideas and eliminating the bad ones. Well-prepared projects will lead to good results and thus achieve the desired return on investment for the organization. This process occurs before the project has begun, and thus can be referred to as the pre-project process. When and how to do the appropriate methods is selected for the small or big projects? Skill, Tools, and Techniques PMBOK or PRINCE2?

\section{The Importance of Research}

The PRINCE2 method one of project management PRINCE2 is a special method of project management in which all project steps are defined at the beginning, and PRINCE2 is based on dividing down a project into procedures, such as the first step (hiring the team)

The second step (supplying ...), and so on.

The PRINCE2 methodology is used to manage various projects, while it was initially intended for PRINCE2 projects.

PRINCE2 is new Knowledge so can use in Small Projects and Big Projects, learning from previous experience, All of Team of Project contributes to its success.

\section{Environmental Impact Assessment}

Determine the positive and negative environmental impacts, analyze these impacts, and benefit from the positive project environment.

Analyzing these effects to determine the most important effects on the environment and the extent of their influence on the work and surrounding environment. The long-term and short-term impacts, direct and indirect effects, and potential risks must also be taken into consideration.

- Prediction \& Mitigation: Environmental impact assessment monitoring is the planned and systematic collection of environmental data to meet specific environmental goals and needs.

- Technical, scientific, structure, and environmental information. 
- Data on the economic and technological features of the environment EIA (Environmental Impact Assessment) [2].

\section{Standards in Projects}

Standards are considered the norm and samples of objects that can be compared with such other phenomena. We can call the document level that specifies the rules, regulations, and requirements to assess adherence to them in the workforce only between the first and second definitions. The first important distinction is consistent with the ideal and the second contains only a recommendation on how to deal with her.

Where there was a variety of project management methodology and standards to summarize the requirements and quality of work.

The development of various techniques for project management has been conducted on this basis. Logically, there is a need to define what qualities and skills are the most important steps that must be taken for the project manager to be a successful leader [4][15].

\subsection{Types of standards}

To define project management standards, best practices have been analyzed and synthesized. To achieve this, management uses two components:

The existence of a self that considers individual projects and the entire company along with the requirements for qualifying project managers as follows:

- Define and understand the terminology, aspects of the activity in this area, and the role of all participants in the project.

- Ensure development and management professionals who practice design types of activity and increase the efficiency of these projects. The project management criteria can be divided into four types: International, national, industry, and enterprise.

\subsubsection{PMI Standards Institute:}

Project management technology was developed that began in the United States of America in the 1960s and was affected by several factors, the most important of which became the nuclear age and the competition with the Soviet Union to invade space and develop new defense strategies that were there based on PMI standards around the world. PMP is a registered mark of the Project Management Institute Foundation [3].

\subsubsection{ISO standard}

It is the oldest and strongest international organization dedicated to standardizing almost all areas of business and technology. It is the leader in restriction at the global level. It has the right to introduce any new standards into the system. ISO International Organization for Standardization [5]. 


\subsubsection{The PRINCE2 standard}

It stands for (Project Management in Controlled Environments) as a general framework for project management and is suitable for managing any type of project and in any industry. Project management has set another standard in the UK owned by AXELOS Limited (a joint venture with the UK government) and set clear instructions for reliability restrictions for effective project implementation despite the limited scope of the standard set in England in the IT industry (PRINCE1) design and development and the launch of a market for new products in engineering and the public sector.

The PRINCE2 methodology uses stage management and margin of tolerance as the main elements of project control. Margins of tolerance allow management to be exempt, that is, when these margins are exceeded and an exception occurs, the project board cannot make the necessary decisions on a case-bycase basis.

The base methodology includes sectors, plans, organization, quality, and risks, among other things in the application of this project. Quality management standards for groups that need to be monitored. There is a continuous adjustment of the environment, and a generation of products are often used on seven principles, subjects, and processes it is considered the most widespread professional certificate in project management [6][1][20].

\section{Learning from experience}

In PRINCE2, the recording and transfer of experiences must take place throughout the project, by documenting any lessons that could be learned from applying them to other projects.Clearly defined roles and responsibilities within the PRINCE2 project the roles and responsibilities of each are defined within a clear organizational structure that takes into account the interests of investors, users, and suppliers. PRINCE2 helps control an ever-changing project environment by providing the necessary tools to the Project Manager [4][12],[18],[23].

\section{PRINCE2 Themes}

This criterion has seven axes: business condition, organization, quality, plans, risks, change, and progress of work. Fig. 1 six performance objectives/Themes PRINCE2.

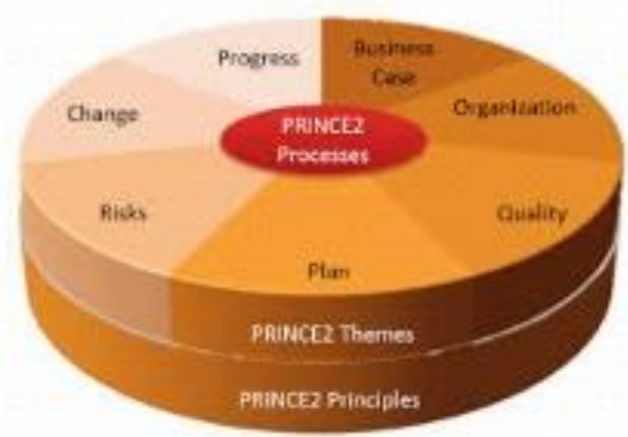

Fig. 1. Themes / Processes PRINCE2 (Web site) 
PRINCE2 is a project management method that covers all six project variables: timelines, prices, quality, benefits, scope, and risks. Six factors are referred to as competing project constraints in the PMBOk [9][16][17].

\subsection{Structure of PRINCE2}

The PRINCE2 method is divided into four components, each of which is represented by the term Elements (sometimes known as integrated elements). Principles, characteristics, methods, and procedures are examples of these components.

Operations: Procedures and activities are being carried out during the project and also processes that answer the question of "What products do they wish to generate and when?"

The specialized aspects highlight the fact that PRINCE2 is a highly general framework that can be used for any project. As a result, PRINCE2 does not provide specific project-specific knowledge, such as the optimum way to build a financial project organization or how to maximize the benefits of a specialized financial product.

Detailed techniques: Many techniques, such as the (CPM) critical path method or the best way to run a brainstorming workshop, can be used during a project. PRINCE2 suggests that you choose the proper technologies for your project, but it doesn't tell you how to do it. Product-based planning and the quality review approach are covered in PRINCE2.[26],[27]

\subsection{Benefits of Using PRINCE2}

Benefits to applying the project management technique to PRINCE2:

- Best Practice: PRINCE2 has been used in hundreds of projects for over 30 years, and it continues to learn from them. As a result, all of the comments, recommendations, and learning from other techniques and conversations have helped PRINCE2 become a best practice.

- PRINCE2 is a project management method that may be used for a range of tasks. As a result, PRINCE2 may be applied for both small and large projects, such as election management, conference planning, bridge building, and IT projects.

- PRINCE2 establishes a framework for functions and responsibilities (also known as "Tasks roles and responsibilities"). Everyone in the team of the project has to understand what is expected this is especially crucial for project managers, who have a responsibility to ensure that activities are done according to plan.

- PRINCE2 concentrates on the product that is clearly defined at the start of the project and is fully understood by all stakeholders. As a result, everyone is on the same page regarding what they're working on and what the final product should be.

- PRINCE2 employs exception management. This permits the project manager to resolve some project difficulties, but once one of the tolerance issues is bypassed, the situation 
should be escalated to the next higher management layer. There will be less management. [10][29],[27].

- Throughout the project life cycle, PRINCE2 continues to evaluate the project's viability from the viewpoint of the Business Case. If at any time throughout the project, the projected return on investment is no longer possible, the project should be discontinued.

- For reporting and management products, PRINCE2 has a well-defined structure. PRINCE2 refers to any document generated to aid in project management as "Management Products," which includes the Project Brief, Business Case, Project Plan, Recognition Reports, and End-of-Stage Report.

- PRINCE2 supports professional development and a strong belief (also known as 'lessons learned). We encourage you to learn from other projects at the start of the project to add a lesson log during the project transfer the lessons to future projects at the end of the project.[28],[30].

\section{Principles}

\subsection{Persistence of Business Justification}

The PRINCE2 project should have a continuous justification for the business reason for starting the project should make sense from the business point of view and there must be a clear return on investment. For example, the project will cost 20,000 euros, but during the first two years, it will save the company 80,000 euros. Does the project have commercial justifications?

The business case document explains the complete business case details, explaining the reason for implementing the project, expected costs and benefits, and timelines. Business Justification Information is another name for these resources. Because the business case is one of the first documents generated for a project, it will prevent certain initiatives from being started from real benefits for the firm. The business justification is then validated throughout the project's life cycle. This might happen, for example, at the end of each step.[7][15],[16].

\subsection{Learning From Experience}

The PRINCE2 project team must learn from past projects, therefore they must take the initiative to uncover past lessons learned and use them throughout the project's life.

As previously said, each project is unique, which means there is always something new to consider, which adds to the risk factor.

PRINCE2 encourages project teams to take the lead. It is necessary to learn from similar projects that may have been carried out within the same company, and if not, to get advice from other external sources (for example, bring in outside consultants).[22],[25].

\subsection{Defined Roles and Responsibilities}


According to PRINCE2, a project's roles and responsibilities should be established and agreed upon within an organizational structure that includes the interests of business stakeholders, users, and suppliers.

Because projects might include employees from many departments or organizations, Critical that the project has defined in team structure managing the project may be impossible.

Business sponsors, users, and suppliers are the project's three major stakeholders, according to PRINCE2.

- $\quad$ Business sponsors ensure that a business provides good value.

- Users are who will use the products once they have been developed and will receive the benefits.

- Suppliers provide resources and experience to the project and product development process. The three primary stakeholders must be properly represented on the project management team.[21]

\subsection{Management of stages}

A good way to do any big task or project is to break it down into manageable parts. In PRINCE2 we refer to the manageable parts as stages. They are called management stages. The PRINCE2 project is planned, monitored, and controlled stage basis. These are referred to as the management stages.

The project board analyzes the performance of the previous stage, the feasibility study, and the plan for the next stage after each stage and determines whether to advance to the next step. When a project includes a lot of phases, the project board has greater influence over it, but it also means they have more work. Because there are fewer stages in the project, top management will have less influence and the project board will have fewer jobs.[[17][27]

\subsection{Focus Products}

Detailed product descriptions will guide the project, build correct expectations, and help deliver the desired products. The PRINCE2 manual states the following: The PRINCE2 project focuses on the identification and delivery of products, in particular, their quality requirements.

Good product descriptions provide clarity because they define the purpose, composition, derivation, and formatting of the product, quality standards, and quality method. A good product description also facilitates the identification of resource requirements, approvals, and activities.

\section{6 plan for the current stage}

Ascertain that future stage plans can benefit from previous and past tasks, for example, if one team produces its products faster than planned, this may be factored into the following stage's planning. There are at least two management phases in a project: the initiation phase and another management phase the project closing process is part of the second phase in a two-stage project.

\subsection{Management via Exception}


PRINCE2 may not be familiar with, but it is important to understand that, according to the PRINCE2 definition project manager has some flexibility in dealing with factors time, cost, and scope before having to notify the project board if there is or maybe a problem (for example, the cost can change by $10 \%$ ). If the problem is small and still within allowance (for example, cost increase by $5 \%$ - less than allowance $10 \%$ ).

The project manager has to deal with it and he does not have to alert the project board and take their time. Management by exception is used by each level in the project organization to manage the level below. The layer below should notify the above management layer only if there is a major problem outside the scope of the PRINCE2 name for a major issue which means that the problem outside the agreed tolerance is an exception.

Now imagine that you are sitting on the project board if everything is going well, Project manager except for regular reports during the phase and at the end of the phase, unless there is an exception, hence the term "management by exception".

- Quality permitting: creating a new GSM and must keyboard to work for the average user for seven years but you have a tolerance of $\pm 5 \%$.

- Permission range: GSM requirements have mandatory requirements in addition to "nice to have" requirements. So, the project can decide the "nice be" requirements to be included, but it must include the milestones.

- Permit feature: A benefit is a measurable improvement that occurs as a result of one or more stakeholders' initiatives. These are advantages for project participants. Increase marketing share by $5 \%$, for example, or develop a new profitable market segment. Is the project still on schedule to deliver the promised benefits? is one of the questions posed during the project.

- Permission Risks: Again, using the GSM example, there will be a certain level of risk tolerance, and if you hear about something higher than that, you will notify the project board. For example, you discover that the risk is now very high - one provider cannot provide a five mega camera pixel with the correct integration specifications. This might generate more problems for your project [7],[8],[24],[26].

\subsubsection{Coordination or coordination in proportion to the project environment}

A PRINCE2 project should be designed for the size, environment, complexity, relevance, capabilities, and risks of the project. You must customize PRINCE2 to match your project, whether it's a small project like hosting a workshop. PRINCE2 can be used for every type of project.

An introduction to the knowledge of an organization

Let's take a look at what will be covered in this topic of organization.

- $\quad$ The knowledge included in the subject matter organization's purpose

- Some definitions of the organization, what is the project, what is the program.

- The three categories of stakeholders.

- The project board's duties and roles.

- Role of the project manager, description, and required skills. Other project responsibilities include authority change, team manager, and project support. [28]

\section{What happens in the real world?}


Project manager, it's more important to start developing products as soon as possible. You depend on others to make decisions, supply information and perform tasks for you. As a result, it is critical. If you don't get this down on paper and approve it.

The first task a project manager must complete in a project is to determine who is in charge of the project and what their roles and functions all tasks responsibilities are. Start with the executive, who might need a reminder that he's in charge of the project [7],[8].

\subsection{PMBOK Guide}

The PMBOK looks at the project through the eye of the project manager only. The PMBOK is concerned with explaining the skills, touching on the types of tools and techniques that can be used in the project, how and when to use them, and why they are used. PMBOK does not focus much on the nature of other functions in the project but rather focuses on Mainly on the job of the project manager and how this manager deals with other functions, the PMBOK does not discuss too many topics such as governance or benefits realization (with simple explanations of it in the book, and its extensive presence in the Program Management Manual and other PMI publications) [9][10].

\subsection{PMBOK Guide: Strengths}

One of the main strengths of the PMBOK Guide is that it provides a comprehensive set of useful tools and techniques. In total (119) tools and technologies are described or referenced. The Time Management Knowledge Area, for example, has 25 different tools and techniques. This compares with only about forty tools and techniques referenced in the Manual as a whole PRINCE2.

In the PMBOK Guide, knowledge domains can be treated in isolation. Therefore, if the project manager needs to have a better understanding of the earned value analysis to better manage project cost, he can focus on the cost management knowledge area in the PMBOK Guide I would not suggest that simply controlling the project's cost is insufficient; a project that would benefit from the application of the PMBOK Guide's value-earning techniques would still benefit, thus the PMBOK Guide is an excellent resource for a variety of project management programs [9],[10].

\subsection{PMBOK Guide: Weaknesses}

One of the weaknesses is the lack of specific responsibilities for the Project Management Team members. This is vaguely defined as the project team members who directly undertake its management activities.

The overly complex and detailed explanation of some of the elements is the second weakness. Complexity is always a hindrance and delay factor and does not provide aid and assistance, and as just mentioned above, there is anecdotal evidence that might suggest this PMBOK Guide does not do itself well. A small example of this can be found in the section detailing the cost management plan, where it indicates that the plan may define the amount of control by which activity cost estimates are rounded up and down. In my opinion, this detail is not important if we comprehensively look at things. On the other hand, since this evidence is a cognitive guide, the writers may have thought that they might not be able to leave this detail without mentioning it [11]. 


\subsection{PRINCE2: Weaknesses}

The lack of tools and techniques in PRINCE2 is the biggest weakness. PRINCE2 describes two techniques in great detail, namely the Quality Review Method and the Product Based Planning approach. The latter was incorporated into PRINCE activities to develop plans for Guide PMBOK [12]. On other hand, many proven and proven planning and control techniques (such as critical path analysis and valueearning analysis) have been well documented elsewhere, and thus do not need to be replicated in the PRINCE3.

\subsection{PRINCE2: Strength}

The focus on the business case to drive and drive the project decision-making process is PRINCE2's main strength. This helps to ensure that projects continue to notice and realize the desired benefits that they are working on achieving, thus ensuring a return on investment and we find that 'continue/stop' decisions will be taken as a result. The usage of management stages is required to review the updated business case. Another strength of Quality Assurance in Prince2 because of the focus on protection [13].[14][30]

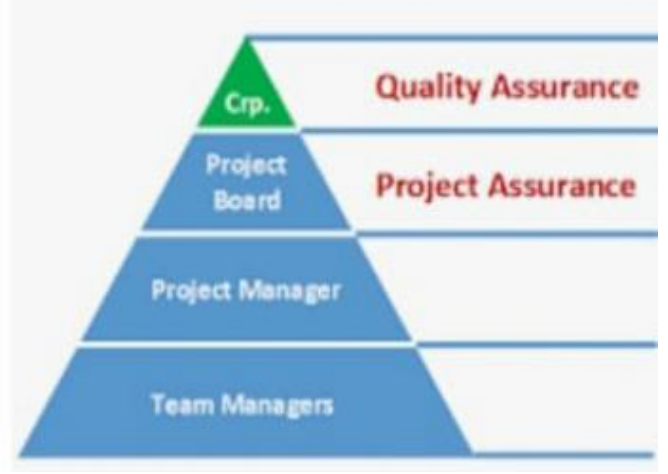

Fig. 2. PRINCE2 Quality Assurance (Web site).

\section{Practical Side to PRINCE2}

They differ in the fact that the first focuses on the information, techniques, and skills that the project manager needs in his work, while the second focuses on the methods and controls required for project management.

PMBOK is considered more comprehensive by covering a greater number of knowledge domains. How to manage schedules and costs and thus increase the percentage of acquired skills for the degree holder.

PRINCE2 focuses on how to successfully manage the project with the lowest level of requirements, and even calls projects that apply the lower levels required by PRINCE2 projects, so PRINCE2 is concerned that the recipient can change his way well according to the nature of his project and his needs, so the PRINCE2 method is more flexible and more adaptable. Accepting the different implementation methods, PRINCE2 usually expects that the powers of 
the project manager are limited and framed in the powers of the executive (the executive position is hardly present in the PMBOK)

The Team of the project in PRINCE2 is responsible for the success project in Scope Time and Quality and Risk, The Product sets out.

Information of Experience previous projects take the Team practical background for a new project that done.[15],[19],[20].

\section{Conclusions}

The following are the summarized remarks of the present work:

1. One of the advantages of working with PRINCE2 is the study of the realistic project environment and the orientation in the investments needed to achieve the expected benefits.

2. The study of the project environment is a study from the bottom of its organizational structure and the study of the external factors surrounding it and the factors that affect the success or failure of the project.

3. Is One of the most important advantages of working with PRINCE2 is the experiences and reports of previous projects, especially those that are similar in the business environment.

4. The work team considers the integrated picture of the success of the project, and it is not the responsibility of the project manager, any experiences are circulated by everyone.

5. project is appropriate to the Iraqi community environment where the changing environment and estimates of project success must be more proportional than failure.

6. More successful in small projects and more flexible to find alternatives that chive project success. Any worker in any profession always makes sure the necessary tools are in the tool kit. Project management does not differ from this example much, just as there are strengths and weaknesses in both the PMBOK Guide and the PRINCE2 Manual, and project management practitioners must learn any "tool" It would be better to use it depending on the surrounding conditions and idea.

\section{References}

[1]AXELOS 2014 UK (wikipedia)

[2] Environmental impact assessment (EIA) ,Lenzen,M,Murray,S.;Korte B.;Dey,C.:A^Guide to best professional practices.

[3] PMBOK® Guide 7.0 from (PMI) Project Management Instiute (United State)

[4] PRINCE2, Meshaal Almanie 201810 November / Transformation Stattragy Progect Lenked in

2021.

[5] Basic Guide PRINCE2 for Dummies /Nic Graham

[6] PRINCE2, for Beginners Btyan Mathis

[7] Frank Turley Practitioner Level. The PRINCE2 Coach

[8] PMBOK Guide ver 7.0 2017,PMI

[9] PMBOK Guide ver 7.0 2017,PM

[10] PMBOK Guide ver 3.0 2013,PMI

[11] PMBOK, http//www.pmi.org

[12] PRINCE2 Sudy Guide bu Divide Hinde 5 june 2018 web sit id.Loc.gov.Isbn 10:111942089978111942089608.

[13] PRINCE2 Guide Registerd Practitioner AMBCS, Yassin Abbas 2015, Knowledge TRAIN July 30/7 PPM 
[14]PRINCE2 Process Map:English ,web:www.ilxgroup.com;AXLOS 2009-2014.

[15]Managing Successful Project with Prince2 :6th edittion Auther :AXELOS.,Great Britain Office.2014 UK,(Wikipedia).

[16]basic Guide/Prince2 for Dummies/Nic Graham

[17]http//www.axelos.com

[18]http:www.goodelearning.com

[19]info@longhallconsulting.com by Longhall Consulting limited Plot 1-7,Muri Okunola street,Victoria Island.

[20]www.Kowledggetrain.com.

[21] https://ae.linkedin.com.

[22]ABAD network for Training , abadnet.com.sa

[23]www.simplileearn.com

[24]PRINCE2 Foundation,6th edition ,https://www.peopecert.org

[25]https://www.quora.com

[26] https://www.prince2.com ,UK

[27]www.Knowledgetrain.com

[28]Prince2 Methodology in Project Management -A Complete Overview ,published on September 24,2021.project copyright 2021 Kissflow.Inc

[29]Managing Successful Project with Prince2 , Great Britain Office, number 9.

[30]Prince2 Key benfet ,21 Jul 2021 by Simon Buehring 